\title{
Are ecstasy users biased toward endorsing somatic mental health symptoms? Results from a general community sample
}

\author{
Amanda M. George • Tim D. Windsor • Bryan Rodgers
}

Received: 22 February 2010 /Accepted: 8 November 2010

(C) Springer-Verlag 2010

\begin{abstract}
Rationale Whether the reported poorer mental health of ecstasy users is due to a bias in endorsement of somatic symptoms has been postulated, but rarely examined.

Objectives The purpose of this study is to investigate whether levels of ecstasy use were associated with differential probabilities of endorsing somatic mental health symptoms.

Methods Current ecstasy users aged 24-30 years $(n=316)$ were identified from a population-based Australian study. Measures included frequency of ecstasy, meth/amphetamine, and cannabis use and the Goldberg anxiety/ depression symptom scales.

Results Multiple indicator, multiple cause models demonstrated no bias towards endorsing somatic symptoms with higher ecstasy use, both with and without adjustment for gender, cannabis, and meth/amphetamine use.

Conclusions Other studies using alternate measures of mental health should adopt this approach to determine if there is a bias in the endorsement of somatic symptoms among ecstasy users.
\end{abstract}

\footnotetext{
A. M. George $(\triangle)$

Centre for Applied Psychology,

University of Canberra,

Canberra ACT, Australia

e-mail: amanda.george@canberra.edu.au

T. D. Windsor

Centre for Mental Health Research,

Australian National University,

Canberra ACT, Australia

B. Rodgers

Australian Demographic and Social Research Institute,

Australian National University,

Canberra ACT, Australia
}

Keywords Ecstasy $\cdot 3$,4-Methylenedioxymethamphetamine (MDMA) · Depression · Anxiety · Mental health · General community sample

\section{Introduction}

The use of methylenedioxymethamphetamine (MDMA), more commonly known as "ecstasy," has been associated with long-term damage to the brain's serotonin 5-HT system in both animals and humans (see Green et al. 2003). It is therefore not surprising that researchers have hypothesized links between 5-HT damage resulting from ecstasy use and psychological conditions related to 5-HT functioning, such as depression (Deakin 1998); however, there has been an overreliance on recruitment of ecstasy users using purposive or snowballing techniques. A number of such studies comparing ecstasy users to both drug naive controls (Gerra et al. 2000; Gerra et al. 2002; Milani et al. 2004) and cannabis or polydrug control groups (de Win et al. 2004; Lamers et al. 2006; Morgan et al. 2002; Soar et al. 2006) have reported poorer mental health assessed via self-reported measures of depressive and/or anxiety symptoms, among ecstasy users relative to non-users.

It is possible, however, that results of studies reporting poorer mental health among ecstasy users are subject to bias resulting from ecstasy users' overreporting of somatic symptoms (Sumnall and Cole 2005). Many self-assessments of mental health administered to ecstasy users, like the Beck Depression Inventory (BDI) include questions regarding sleep difficulties, changes in appetite, and other somatic symptoms (Roiser and Sahakian 2004) which may be consequences of the pharmacological properties of the drug rather than indicators of psychological distress. 
Ecstasy users' lower mental health scale scores could also reflect differences in lifestyle factors associated with ecstasy use. Studies have found that ecstasy users spend more time at parties (Boyd et al. 2003), socialize more with friends, and study less (Strote et al. 2002) relative to nonusers. Acknowledging such characteristics and the frequent purposive recruitment of users from settings like clubs, bars, or raves, suggests that a somatic symptom reporting bias among ecstasy users could also result from lifestyle factors where sleep deprivation, for example, is common. Finally, many ecstasy users are polydrug users and may endorse somatic symptoms which are the result of other drug use.

We are aware of one study that has examined the possibility of a somatic symptom reporting bias among ecstasy users. Roiser and Sahakian (2004) divided the BDI into cognitive and somatic subscales and investigated differences across current and former ecstasy users and drug naive and polydrug control groups. Results found no significant difference between current ecstasy users relative to well-matched polydrug controls for either subscale, but former ecstasy users had significantly higher somatic and cognitive subscale scores relative to drug naive and polydrug controls (Roiser and Sahakian 2004). Thus, this study failed to support the proposal that current users of ecstasy should demonstrate higher somatic scores on depression measures due to lifestyle factors and the pharmacological properties of the drug. Examining subscale differences, however, does not allow for examination of whether ecstasy is associated with specific somatic complaints, such as sleep interruption and changes to appetite.

The current study aimed to examine the relationship of ecstasy use with psychological distress among young adults recruited from the general community in an attempt to avoid the typical purposive recruitment of those from bars/raves, etc. Additionally, the present study aimed to investigate somatic symptom bias among ecstasy users in a methodologically rigorous manner through investigation of somatic and cognitive mental health symptoms among ecstasy users at the scale item level, rather than at the subscale level. The current study determined whether increasing frequencies of ecstasy use were associated with a differential probability of endorsing somatic mental health symptoms using multiple indicator multiple cause (MIMIC) modeling techniques. These techniques enabled assessments of whether frequency of ecstasy use was associated with specific mental health symptoms independent of the association of ecstasy use with the overall measure of mental health. If direct effects to somatic specific items are detected, this means that frequency of ecstasy use has a stronger relationship with these specific symptoms than with the overall mental health factor underlying the symptoms (see Christensen et al. 1999). Importantly, the potentially confounding influences of degree of other drug use were also controlled for when examining the relationship of ecstasy use with mental health symptoms. The following specific research questions were:

1. Are greater frequencies of ecstasy use associated with stronger endorsement of somatic mental health symptoms? and

2. If so, does the result hold with adjustment for other drug use and gender?

\section{Method}

\section{Participants}

Participants were from the PATH Through Life Project, a longitudinal investigation of three age cohorts $(20-24,40$ 44 , and 60-64 years) who will be re-interviewed every 4 years for 20 years. Originally, participants were randomly drawn from the electoral roll of Canberra and the neighboring region of Queanbeyan in Australia. Enrollment to vote is compulsory for Australian citizens aged 18 years and over with very rare exceptions. At wave 1 , there was a $58.6 \%$ response rate for the youngest cohort among those who were contactable.

The current investigation concerns those from the youngest cohort at wave 2 in 2003/2004 (when questions regarding ecstasy use were included) when participants were aged 24-30 years. Of the 2,404 younger participants who completed wave 1 interviews, 2,139 completed wave 2 ( $89 \%$ retention rate). The group used in the analyses were those who reported current ecstasy use at wave $2(n=316)$.

\section{Procedure}

Participants completed a questionnaire using a hand-held computer, with a trained interviewer in the room to answer any questions. Research has shown that computerized self-administered questionnaires are less likely to elicit socially desirable responses compared with paperand-pencil questionnaires (Booth-Kewley et al. 2007; Richman et al. 1999) or personal interviews (Richman et al. 1999). This is important in the current study, given the focus on illicit drug use. Similarly, in a recent review of Web-based methods in illicit substance use research, the advantage of increased confidentiality among respondents was noted (Miller and Sønderlund 2010). This study was approved by the Australian National University Human Research Ethics Committee. 
Questionnaire

\section{Ecstasy use}

If participants had used ecstasy (pills, E, eccy, XTC, and MDMA) in the last year, they were asked how often they currently used ecstasy. The following were the response options: every day, once a week, about once a month, every few months, once or twice a year, less often and finally, do not currently use. Based on responses, current ecstasy users $(n=316)$ were categorized in terms of their frequency of ecstasy use as follows: (1) very infrequent (once or twice a year/less often; $n=151)$, (2) every few months $(n=96)$, (3) monthly $(n=51)$, and (4) weekly $(n=18)$. No participant reported using ecstasy on a daily basis. Participants who had never used ecstasy, had used ecstasy but not in the prior year, or who reported that they "don't currently use" were excluded from the current analysis.

\section{Goldberg's anxiety and depression scales}

Participants completed the Goldberg anxiety and depression scales (Goldberg et al. 1988). These scales are comprised of a nine-item scale measuring anxiety symptoms and a nineitem scale measuring depressive symptoms. Each item asks the participant if they have experienced a particular symptom of depression (e.g., loss of weight, lack of energy) or anxiety (e.g., irritability, poor sleep) in the 4 weeks prior to the interview. The depression and anxiety scales are typically highly correlated, and individual items have been found to load on a common factor representing psychological distress (Jorm et al. 2005). Item response options were dichotomous (yes/no).

Items from the Goldberg scales were identified as "somatic" if they represented depression and anxiety symptoms that had been identified as having a somatic component in previous research. Judgments were based on the somatic item assessments of Roiser and Sahakian (2004) using the BDI, items included in the Brief Symptom Inventory (Derogatis and Melisaratos 1983) somatization subscale and somatic symptoms from the Hamilton Rating Scale for Depression (Troisi et al. 1996). Using this approach, nine items from the Goldberg scales were identified as having a somatic component. These were sleeping poorly, headaches/ neck aches, trembling, etc. (including tingling, dizzy spells, sweating, diarrhea, or needing to pass water more often than usual), difficulty falling asleep, lacking energy, lost weight, been waking early, felt slowed up, and tended to feel worse in the mornings. The remaining nine items were combined to produce a non-somatic subscale. These were difficulty relaxing, felt keyed up, worrying a lot, irritable, lost interest, lost confidence, felt hopeless, difficulty concentrating, and health worry.
Of the 316 current ecstasy users in the sample, there were two missing cases for the Goldberg scales leaving a total of 314 cases for analysis. A preliminary one-factor model led to the deletion of two items: whether lost weight (due to a poor appetite) and whether waking early because, whilst significant, they had particularly low factor loadings. The modification indices in the model output revealed that the model could be improved by allowing the error residuals of "sleeping poorly" and "difficulty falling asleep" to correlate. Consequently, the residual covariance for the items was included in subsequent models, consistent with previous research conducted using the larger PATH dataset (Jorm et al. 2005). Allowing the residuals of conceptually related items to be correlated acknowledges a stronger item-level association than can be explained by the underlying factor (Christensen et al. 1999). With the removal of two items, somatic subscale scores ranged from 0 to 7 and non-somatic subscale scores ranged from 0 to 9 . Total scores on the composite measure of psychological distress therefore ranged from 0 to 16 (summation of both somatic and non-somatic items).

\section{Covariates}

Participants were categorized in terms of their cannabis use as follows: (1) not a current cannabis user $(n=89)$, (2) use cannabis once or twice a year $(n=66)$, (3) use cannabis every 1-4 months $(n=43)$, (4) use cannabis monthly $(n=$ $41)$, and (5) use cannabis weekly $(n=75)$. Current ecstasy users were categorized in terms of their meth/amphetamine use (for non-medical purposes) as follows: (1) not a current meth/amphetamine user ( $n=134$ including 71 ecstasy users who had never tried meth/amphetamines), (2) infrequent use (once or twice a year/less often; $n=93$ ), (3) use every few months $(n=55)$, and (4) use monthly or more $(n=32)$. No other drug use indicators (dosage, etc.) were included in the PATH project.

\section{Statistical procedures}

Data were analyzed using SPSS 17 to examine group differences via the one-way analysis of variance and Pearson's $\chi^{2}$ tests for continuous and categorical variables, respectively. If the overall $\chi^{2}$ was significant, the adjusted standardized residual (AR) was used to examine the levels of the categorical variable in more detail (see Agresti 1996). An alpha level of 0.05 was used for all analyses.

MIMIC structural equation models (see Jöreskog and Goldberger 1975) were performed using AMOS 17. MIMIC models provide a better method of detecting item bias relative to traditional methods by simultaneously estimating relationships involving an unmeasured latent factor (overall psychological distress) and the observed 
individual items that comprise the latent factor (Christensen et al. 1999; Mast 2005; Muthén 1989). In the current study, MIMIC models allowed the association of frequency of ecstasy use on each specific mental health symptom to be assessed while simultaneously assessing the association of ecstasy with the underlying psychological distress factor. This allowed assessment of whether particular mental health symptoms were associated with a differential probability of endorsement by more frequent ecstasy users when their overall psychological distress was held constant with that of less frequent ecstasy users. Due to the dichotomous nature of the Goldberg response scales (yes/ no), asymptotically distribution-free estimation, which does not require rigid assumptions regarding population distributions, was preferred over maximum likelihood estimation (MacCallum et al. 1996). Model fit was evaluated using the $\chi^{2}$ test as an index of absolute fit and several alternative indices that are less sensitive to sample size (Holbert and Stephenson 2002). These included root mean square error of approximation (RMSEA) (values up to 0.08 indicate satisfactory model fit; Holmes-Smith et al. 2004), goodness of fit index (GFI), comparative fit index (CFI), and nonnormed fit index (NNFI) (values above 0.9 indicate satisfactory fit; Holmes-Smith et al. 2004). A subsequent MIMIC model controlled for the covariates: cannabis use, meth/amphetamine use and gender.

\section{Results}

Descriptive statistics by ecstasy use

Table 1 presents demographic and illicit drug use characteristics for the four current ecstasy using groups. There were no significant differences across groups for somatic, nonsomatic, and overall psychological distress scores or in terms of gender distribution. The analyses showed that ecstasy grouping was contingent upon frequency of cannabis use $\left[\chi^{2}(12)=23.16, p=0.03\right]$ and frequency of meth/amphetamine use $\left[\chi^{2}(9)=125.27, p<0.001\right]$. A

Table 1 Gender, mental health, cannabis and meth/amphetamine use by frequency of ecstasy use groupings

\begin{tabular}{|c|c|c|c|c|c|}
\hline & & \multicolumn{4}{|c|}{ Frequency of ecstasy use } \\
\hline & & Infrequent & Every few months & Monthly & Weekly \\
\hline & & $n=151$ & $n=95$ & $n=51$ & $n=17$ \\
\hline $\operatorname{Sex}$ & $\%$ & & & & \\
\hline Male & & 58.3 & 57.9 & 70.6 & 76.5 \\
\hline Female & & 41.7 & 42.1 & 29.4 & 23.5 \\
\hline Psychological distress $^{\mathrm{a}}$ & $\mathrm{M} \pm \mathrm{SD}$ & $6.02 \pm 4.66$ & $6.92 \pm 4.86$ & $6.43 \pm 5.16$ & $7.17 \pm 5.71$ \\
\hline Somatic items $\mathrm{s}^{\mathrm{b}}$ & & $2.64 \pm 2.23$ & $2.96 \pm 2.17$ & $2.64 \pm 2.28$ & $2.53 \pm 2.67$ \\
\hline Non-somatic items ${ }^{\mathrm{c}}$ & & $3.38 \pm 2.76$ & $3.97 \pm 3.11$ & $3.78 \pm 3.30$ & $4.65 \pm 3.37$ \\
\hline Frequency of cannabis use & $\%$ & & & & \\
\hline Weekly & & 23.8 & 18.9 & 31.4 & 29.4 \\
\hline Monthly & & 7.3 & 21.1 & 17.6 & 5.9 \\
\hline Every $1-4$ months & & 13.2 & 12.6 & 15.7 & 17.6 \\
\hline Less often & & 20.5 & 25.3 & 19.6 & 5.9 \\
\hline Not currently using & & 35.1 & 22.1 & 15.7 & 41.2 \\
\hline Frequency of meth/amphetamine use & $\%$ & & & & \\
\hline Monthly+ & & 1.3 & 5.3 & 31.4 & 52.9 \\
\hline Every few months & & 4.0 & 31.6 & 31.4 & 17.6 \\
\hline Less often & & 36.4 & 29.5 & 17.6 & 5.9 \\
\hline Not currently using & & 58.3 & 33.7 & 19.6 & 23.5 \\
\hline $\begin{array}{l}{ }^{\text {a }} \text { Score derived from a total of Goldberg } \\
\text { findings from the one-factor congeneric } \\
\text { health symptoms in the previous } 4 \text { weel }\end{array}$ & $\begin{array}{l}\text { and depress } \\
\text { fit indices. }\end{array}$ & $\begin{array}{l}\text {, with the ite } \\
\text { scores range }\end{array}$ & $\begin{array}{l}\text { tweight (due to poor a } \\
\text { to16 with higher scor }\end{array}$ & $\begin{array}{l}\text { " and "waking } \\
\text { ative of exper }\end{array}$ & $\begin{array}{l}\text { leleted as per } \\
\text { more mental }\end{array}$ \\
\hline $\begin{array}{l}{ }^{\mathrm{b}} \text { Somatic items included sleeping poorl } \\
\text { worse in the mornings. Possible scores }\end{array}$ & $\begin{array}{l}\text { ches/neck } \\
\text { m } 0 \text { to } 7\end{array}$ & mbling, etc., & ty falling asleep, lack & gy, feeling slo & , and feeling \\
\hline
\end{tabular}


greater proportion of monthly and weekly ecstasy users reported using meth/amphetamines frequently (monthly or more). Patterns for cannabis use were less clear. For example, $41 \%$ of weekly ecstasy users reported not using cannabis.

\section{MIMIC models}

Table 2 presents the proportion of each ecstasy using the group who endorsed a specific item (including waking early and lost weight due to poor appetite which were not included in MIMIC models, as described previously) in relation to how they were feeling in the 4 weeks prior to the interview. Pearson's $\chi^{2}$ tests found that the endorsement of each item was not contingent upon the ecstasy group $(p<$ 0.05 ) with the exception of "lost confidence" which just reached statistical significance, $\chi^{2}(3)=8.11, p=0.048$. An examination of the ARs revealed that a lower proportion of infrequent ecstasy users, but a higher proportion of those using the drug every few months, endorsed this item. The lack of association between the two excluded items and the ecstasy group indicates that their removal was unlikely to impact upon findings in the MIMIC models.
The MIMIC models were designed to see whether level/ frequency of ecstasy use was associated with a differential probability of specific item endorsement independent of the association of frequency of ecstasy use with overall psychological distress. The first MIMIC model included ecstasy only as a predictor of the latent variable representing psychological distress and its component items. The fit statistics for model 1 (ecstasy only) indicated good model fit $\left[\chi^{2}(103)=252.01, p<0.001 ; \mathrm{RMSEA}=0.07\right.$; CFI $=0.93$; $\mathrm{NNFI}=0.90 ; \mathrm{GFI}=1.00]$. The model demonstrated that increases in frequency of ecstasy use were not associated with the overall measure of psychological distress, but were associated with a significantly increased endorsement of the following items: "difficulty concentrating," "lost confidence," "lost interest," and "difficulty falling asleep." Increases in frequency of ecstasy use were also associated with decreased endorsement of having had "headaches/neck aches."

Figure 1 presents the structure of model 2 which extended the first MIMIC model by controlling for cannabis use, meth/amphetamine use, and gender. In the model, each covariate had a path to the latent variable and in addition, a path to each individual mental health

Table 2 Percentage of each ecstasy group endorsing specific items on the measure of psychological distress (Goldberg depression and anxiety scales)

Frequency of ecstasy use

Infrequent $(n=151) \quad$ Every few months $(n=95) \quad$ Monthly $(n=51) \quad$ Weekly $(n=17)$

\begin{tabular}{|c|c|c|c|c|}
\hline \multicolumn{5}{|l|}{ Somatic items } \\
\hline Lacking energy & 47.7 & 52.6 & 45.1 & 41.2 \\
\hline Sleeping poorly & 33.8 & 38.9 & 35.3 & 29.4 \\
\hline Headaches or neck aches & 45.0 & 46.3 & 29.4 & 23.5 \\
\hline $\begin{array}{l}\text { Trembling, tingling, dizzy spells, sweating, } \\
\text { diarrhea, or passing water more often than usual }\end{array}$ & 27.8 & 31.6 & 29.4 & 41.2 \\
\hline Difficulty falling asleep & 33.1 & 45.3 & 43.1 & 35.3 \\
\hline Felt slowed up & 33.8 & 34.7 & 43.1 & 29.4 \\
\hline Tended to feel worse in mornings & 43.0 & 46.3 & 39.2 & 52.9 \\
\hline \multicolumn{5}{|l|}{ Non-somatic } \\
\hline Difficulty relaxing & 42.4 & 41.1 & 43.1 & 52.9 \\
\hline Felt keyed up or on edge & 46.4 & 49.5 & 43.1 & 52.9 \\
\hline Worrying a lot & 50.3 & 52.6 & 45.1 & 58.8 \\
\hline Irritable & 43.7 & 54.7 & 47.1 & 70.6 \\
\hline Lost interest in things & 33.1 & 40.0 & 35.3 & 58.8 \\
\hline Lost confidence in yourself & 23.2 & 38.9 & 33.3 & 41.2 \\
\hline Felt hopeless & 22.5 & 28.4 & 29.4 & 41.2 \\
\hline Difficulty concentrating & 36.4 & 46.3 & 54.9 & 47.1 \\
\hline Worried about your health & 39.7 & 45.3 & 47.1 & 41.2 \\
\hline \multicolumn{5}{|l|}{ Deleted items } \\
\hline Lost weight (due to poor appetite) & 11.3 & 21.1 & 17.6 & 29.4 \\
\hline Been waking early & 41.7 & 46.3 & 33.3 & 58.8 \\
\hline
\end{tabular}


Fig. 1 MIMIC model design for assessing the effects of frequency of ecstasy use on psychological distress whilst also examining the effect of frequency of ecstasy use on each individual mental health item (gender, cannabis use, and meth/ amphetamine use were controlled for in the second model). For ease of interpretation, not all paths are shown. An example path is shown from ecstasy to one psychological distress item (a) and a path from ecstasy to the latent factor of psychological distress is shown (b). In each full model, there are paths from ecstasy, cannabis, meth/amphetamines and gender to the latent factor as well as a path to each psychological distress item

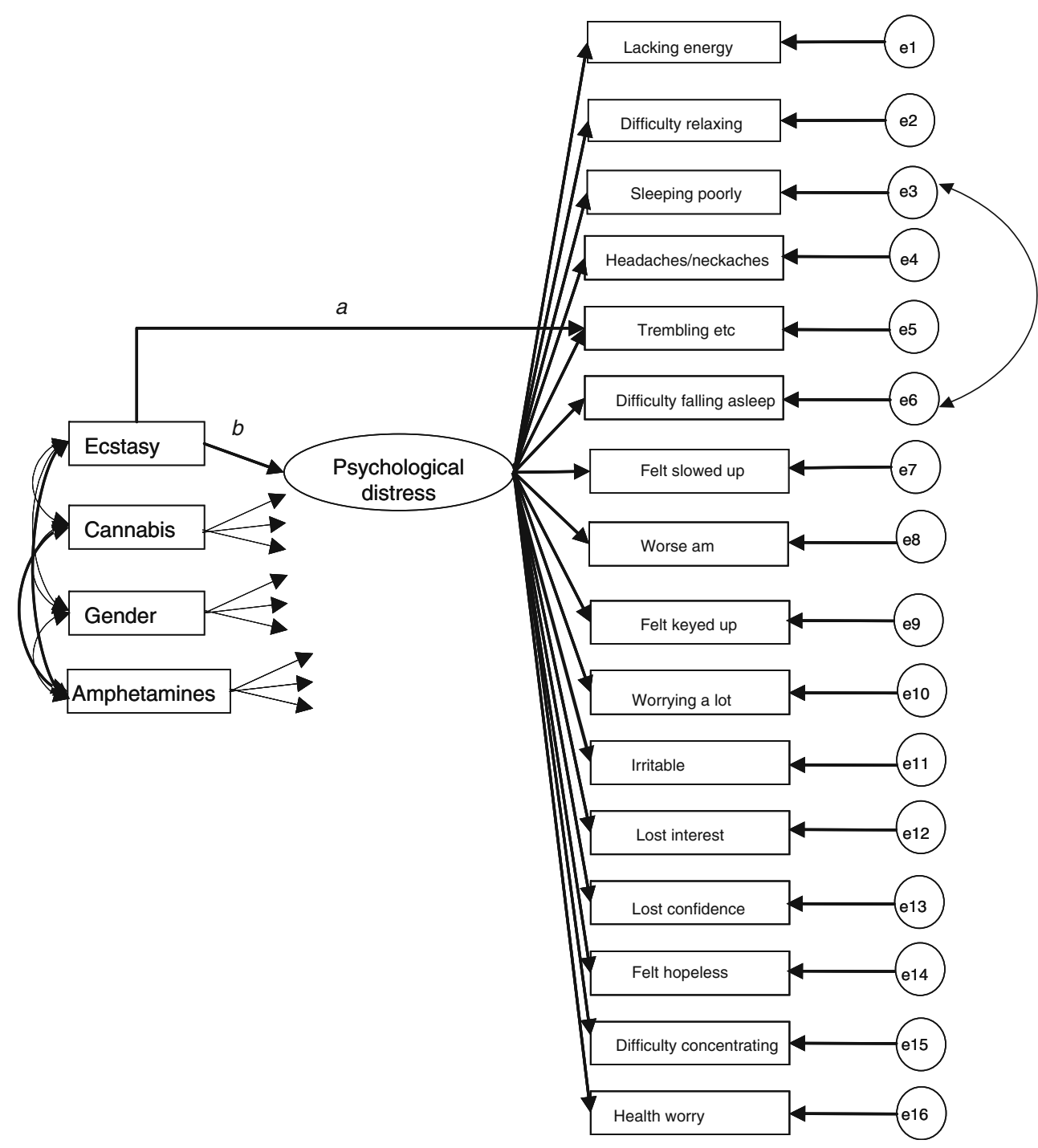

symptom. One of the paths from each covariate to an individual item needed to be constrained to zero. This path then served as a reference point against which the effects of frequency of ecstasy use to other item paths were assessed (Christensen et al. 1999). In order to determine which covariate-item path was constrained to zero, a series of 16 models were performed. These assessed the effect of each covariate on each individual item. The item which had the weakest association across all three covariates was "lacking energy," and this was constrained to zero and thereby served as the reference point.

Once again, the model showed good fit $\left[\chi^{2}(103)=\right.$ 234.71, $p<0.001 ; \mathrm{RMSEA}=0.06 ; \mathrm{CFI}=0.97$; $\mathrm{NNFI}=0.95$; $\mathrm{GFI}=1.00]$. In this model, all coefficients moved in a negative direction and no additional paths became significant with adjustment for the covariates. Post hoc analyses revealed that these reductions were not due to adjustment for any single factor. Table 3 displays the standardized path coefficients to each individual item for frequency of ecstasy use in both models.

\section{Discussion}

The current study aimed to determine whether greater frequencies of ecstasy use were associated with increased endorsement of somatic rather than non-somatic mental health symptoms. It was also one of the few investigations to examine the mental health of ecstasy users recruited from the general community, rather than through purposive recruitment methods. Whilst weekly ecstasy users demonstrated the highest total psychological distress score (and non-somatic subscale score), there was no statistically significant difference across frequency of ecstasy use categories. Results also failed to show increased somatic symptom scores with increasing frequency of ecstasy use. 
Table 3 Standardized regression coefficients for frequency of ecstasy use on psychological distress (Goldberg anxiety and depression) items

Model 1

\begin{tabular}{|c|c|c|}
\hline & Model 1 & $\begin{array}{l}\text { Model } 2 \text { (controlled for gender, } \\
\text { cannabis use and } \\
\text { meth/amphetamine use) }\end{array}$ \\
\hline \multicolumn{3}{|l|}{ Somatic items } \\
\hline Lacking energy & - & - \\
\hline Sleeping poorly & 0.08 & -0.08 \\
\hline Headaches/neck aches & $-0.10 *$ & $-0.19 *$ \\
\hline \multicolumn{3}{|c|}{$\begin{array}{l}\text { Trembling, tingling, dizzy spells, } \\
\text { sweating, diarrhea or passing }\end{array}$} \\
\hline water more often than usual & 0.03 & -0.15 \\
\hline Difficulty falling asleep & $0.14 *$ & 0.07 \\
\hline Felt slowed up & 0.07 & 0.07 \\
\hline Worse in mornings & 0.05 & 0.02 \\
\hline \multicolumn{3}{|l|}{ Non-somatic items } \\
\hline Difficulty relaxing & 0.03 & -0.06 \\
\hline Felt keyed up & 0.02 & -0.04 \\
\hline Worrying a lot & 0.06 & -0.01 \\
\hline Irritable & 0.07 & 0.01 \\
\hline Lost interest & $0.09 *$ & -0.01 \\
\hline Lost confidence & $0.18 *$ & 0.11 \\
\hline Felt hopeless & 0.09 & 0.02 \\
\hline Difficulty concentrating & $0.11 *$ & 0.04 \\
\hline Health worry & 0.03 & 0.04 \\
\hline
\end{tabular}

$* p<.05$, significant effects

- This item was constrained to zero and serves as a reference point which the effects of frequency of ecstasy use to other item paths was assessed

Examination at the item level found that endorsement of the specific items of difficulty concentrating, lost confidence, lost interest, and difficulty falling asleep on a measure of psychological distress were associated with increases in the frequency of ecstasy use independent of the association of ecstasy use with the latent measure of psychological distress (which was non-significant). Only one of these items (difficulty falling asleep) was somatic. Also, reporting having had headaches was more frequently endorsed as ecstasy use declined in frequency. Although the effect for headaches/neck aches remained, adjustment for cannabis, meth/amphetamine use, and gender reduced all other effects to non-significance. Results also showed that no single covariate was responsible for all of the reductions in these effects.

Overall, results from the current investigation suggest that greater frequencies of ecstasy use are not associated with stronger endorsement of somatic mental health symptoms at both the item and subscale level. The importance of controlling for other drug use in the examination of ecstasy and mental health has been established; however, the lack of significant findings for somatic items cannot be attributed to the control for other drug use in the current investigation-results failed to demonstrate a somatic symptom reporting bias with increases in ecstasy use frequency even before the effects of cannabis use, meth/amphetamine use, and gender were adjusted for.

Some ecstasy users in the current sample were using the drug regularly (monthly or more) and yet, even among these frequent users, a bias toward endorsement of somatic mental health symptoms was not detected. The reference period for the measure of psychological distress was 4 weeks. As such, it is also likely that those who reported use of ecstasy on a monthly or weekly basis had taken the drug in the 4 weeks prior to the interview. If it were the case that endorsement of mental health items was a reflection of the acute/subacute effects from the pharmacological properties of the drug or else, lifestyle factors associated with its use, it would be expected that frequent users in the current sample would have demonstrated a bias toward somatic mental health symptom endorsement. What was identified, however, was that weekly ecstasy users had the highest score on the measure of non-somatic mental health 
symptoms. This was not statistically significant, but this may be because of the low sample size of weekly users $(n=$ 17). Such results suggest that frequent ecstasy users are more likely to endorse non-somatic, rather than somatic, mental health symptoms. Whether this is due to acute/ subacute effects or a reflection of actual symptoms is unknown in the current investigation.

Assessments of mental health among ecstasy users have typically been based on BDI (i.e., Hanson and Luciana 2004; MacInnes et al. 2001; Roiser et al. 2005), the SCL90, or the related BSI or SCL-90R (i.e., Milani et al. 2005; Milani et al. 2004; Morgan et al. 2002; Parrott et al. 2001; Thomasius et al. 2003). Establishing whether these and other commonly used measures produce mental health scores that are subject to somatic symptom reporting bias requires further investigation, as the results from the current study cannot be generalized to studies which have used alternative measures and samples; however, the present study makes an important contribution to the literature by demonstrating a rigorous methodological approach to the examination of somatic symptom bias that can be applied in future research concerned with ecstasy use and mental health.

There were several additional strengths to this study. This work presents the first study we are aware of to empirically examine whether frequency of ecstasy use is associated with a potential somatic symptom reporting bias through examination at the individual item level, rather than investigation of somatic/cognitive subscale scores. Second, the study used participants from a general community sample and thus, provided a rare insight into the mental health of ecstasy users not recruited by purposive means. Third, the study considered degree of ecstasy use (frequency) and controlled for use of other relevant illicit substances which are often ignored in examining the relationships of ecstasy use with mental health.

The narrow age bracket and geographical distribution of the sample limit generalization of these findings, and alternative measures of ecstasy use, such as usual number of pills consumed, which were not assessed within the PATH project, may have altered results. Additionally, information regarding lifestyle factors was not included in the current study. The removal of two somatic items (waking early and lost appetite) due to their poor factor loadings in the one-factor congeneric model reduced our capacity to examine somatic symptom bias; however, statistical analyses prior to the MIMIC models revealed that endorsement of these items was not contingent upon frequency of ecstasy use. Thus, their exclusion was unlikely to have altered the findings.

Future research using alternate assessments of mental health is required to better determine whether assessments of the mental health of ecstasy users based on validated psychometric instruments are likely to be accurate and not an artifact of bias in the endorsement of somatic symptoms. Whilst the general community sampling methodology employed within the current investigation was a notable strength, it would be worthwhile to replicate findings with a more experienced sample of ecstasy users. In the absence of more studies which have investigated the possibility of a somatic symptom reporting bias among ecstasy users, it would be advantageous for researchers to include multiple assessments of mental health when examining the association of ecstasy use with depressive or anxiety symptoms and, of course, ensure that important confounders are adequately controlled when investigating these relationships.

Acknowledgements We thank Patricia Jacomb, Karen Maxwell, Helen Christensen, Tony Jorm, Kaarin Anstey, and the PATH interviewing team and participants in this study. Funding was provided by the National Health and Medical Research Council (NMHRC), program grant no. 179805. Bryan Rodgers is supported by the NHMRC Research Fellowship (no. 471429). Tim Windsor is supported by an NHMRC capacity building grant in population health research (no. 418020).

\section{References}

Agresti A (1996) An introduction to categorical data analysis. John Wiley \& Sons, New York

Booth-Kewley S, Larson GE, Miyoshi DK (2007) Social desirability effects on computerized and paper-and-pencil questionnaires. Comput Hum Behav 23:463-477

Boyd CJ, McCabe SE, d'Arcy H (2003) Ecstasy use among college undergraduates: gender, race and sexual identity. J Subst Abuse Treat 24:209-215

Christensen H, Jorm AF, Mackinnon AJ, Korten AE, Jacomb PA, Henderson AS, Rodgers B (1999) Age differences in depression and anxiety symptoms: a structural equation modelling analysis of data from a general population sample. Psychol Med 29:325-339

Deakin JF (1998) The role of serotonin in panic, anxiety and depression. Int Clin Psychopharmacol 13:1-5

Derogatis LR, Melisaratos N (1983) The Brief Symptom Inventory: an introductory report. Psychol Med 13:595-605

de Win MML, Reneman L, Reitsma JB, den Heeten GJ, Booij J, van den Brink W (2004) Mood disorders and serotonin transporter density in ecstasy users - the influence of long-term abstention, dose, and gender. Psychopharmacology 173:376-382

Gerra G, Zaimovic A, Ferri M, Zambelli U, Timpano M, Neri E, Marzocchi GF, Delsignore R, Brambilla F (2000) Long-lasting effects of (+/-)3, 4-methylenedioxymethamphetamine (ecstasy) on serotonin system function in humans. Biol Psychiatry 47:127136

Gerra G, Zaimovic A, Moi G, Giusti F, Gardini S, Delsignore R, Laviola G, Macchia T, Brambilla F (2002) Effects of (+/-) 3, 4methylene-dioxymethamphetamine (ecstasy) on dopamine system function in humans. Behav Brain Res 134:403-410

Goldberg D, Bridges K, Duncan-Jones P, Grayson D (1988) Detecting anxiety and depression in general medical settings. Br Med J 297:897-899

Green AR, Mechan AO, Elliott JM, O'Shea E, Colado MI (2003) The pharmacology and clinical pharmacology of 3, 4- 
methylenedioxymethamphetamine (MDMA, "ecstasy"). Pharmacol Rev 55:463-508

Hanson KL, Luciana M (2004) Neurocognitive function in users of MDMA: the importance of clinically significant patterns of use. Psychol Med 34:229-246

Holbert RL, Stephenson MT (2002) Structural equation modeling in the communication sciences, 1995-2000. Hum Commun Res 28:531-551

Holmes-Smith P, Coote L, Cunningham E (2004) Structural equation modelling: from the fundamentals to advanced topics. School Research Evaluation and Measurement Services, Melbourne

Jöreskog KG, Goldberger AS (1975) Estimation of a model with multiple indicators and multiple causes of a single latent variable. Journal of the American Statistical Association 70:631-639

Jorm AF, Windsor TD, Dear KBG, Anstey KJ, Christensen H, Rodgers B (2005) Age group differences in psychological distress: the role of psychosocial risk factors that vary with age. Psychol Med 35:1253-1263

Lamers CT, Bechara A, Rizzo M, Ramaekers JG (2006) Cognitive function and mood in MDMA/THC users, THC users and nondrug using controls. J Psychopharmacol 20:302-311

MacCallum RC, Browne MW, Sugawara HM (1996) Power analysis and determination of sample size for covariance structure modeling. Psychol Meth 1:130-149

MacInnes N, Handley SL, Harding GF (2001) Former chronic methylenedioxymethamphetamine (MDMA or ecstasy) users report mild depressive symptoms. J Psychopharmacol 15:181-186

Mast BT (2005) Impact of cognitive impairment on the phenomenology of geriatric depression. Am J Geriatr Psychiatry 13:694-700

Milani RM, Parrott AC, Turner JJ, Fox HC (2004) Gender differences in self-reported anxiety, depression, and somatization among ecstasy/MDMA polydrug users, alcohol/tobacco users, and nondrug users. Addict Behav 29:965-971

Milani RM, Parrott AC, Schifano F, Turner JJD (2005) Patterns of cannabis use in ecstasy polydrug users: moderate cannabis use may compensate for self-rated aggression and somatic symptoms. Hum Psychopharmacol 20:249-261

Miller PG, Sønderlund AL (2010) Using the internet to research hidden populations of illicit drug users: a review. Addiction 105:1557-1567
Morgan MJ, McFie L, Fleetwood LH, Robinson JA (2002) Ecstasy (MDMA): are the psychological problems associated with its use reversed by prolonged abstinence? Psychopharmacology 159:294-303

Muthén BO (1989) Using item-specific instructional information in achievement modeling. Psychometrika 54:385-396

Parrott AC, Milani RM, Parmar R, Turner JJD (2001) Recreational ecstasy/MDMA and other drug users from the UK and Italy: psychiatric symptoms and psychobiological problems. Psychopharmacology 159:77-82

Richman WL, Weisband S, Kiesler S, Drasgow F (1999) A metaanalytic study of social desirability distortion in computeradministered questionnaires, traditional questionnaires, and interviews. J Appl Psychol 84:754-775

Roiser JP, Sahakian BJ (2004) Relationship between ecstasy use and depression: a study controlling for poly-drug use. Psychopharmacology 173:411-417

Roiser JP, Cook LJ, Cooper JD, Rubinsztein DC, Sahakian BJ (2005) Association of a functional polymorphism in the serotonin transporter gene with abnormal emotional processing in ecstasy users. Am J Psychiatry 162:609-612

Soar K, Turner JJ, Parrott AC (2006) Problematic versus nonproblematic ecstasy/MDMA use: the influence of drug usage patterns and pre-existing psychiatric factors. J Psychopharmacol $20: 417-424$

Strote J, Eun Lee J, Wechsler H (2002) Increasing MDMA use among college students: results of a national survey. J Adolesc Health 30:64-72

Sumnall HR, Cole JC (2005) Self-reported depressive symptomatology in community samples of polysubstance misusers who report ecstasy use: a meta-analysis. J Psychopharmacol 19:8492

Thomasius R, Petersen K, Buchert R, Andresen B, Zapletalova P, Wartberg L, Nebeling B, Schmoldt A (2003) Mood, cognition and serotonin transporter availability in current and former ecstasy (MDMA) users. Psychopharmacology 167:85-96

Troisi A, Pasini A, Gori G, Sorbi T, Baroni A, Ciani N (1996) Clinical predictors of somatic and psychological symptoms of depression in Alzheimer's disease. Int J Geriatr Psychiatry $11: 23-27$ 